\title{
Interaction between primary and secondary sporocysts of Schistosoma mansoni and the internal defence system of Biomphalaria resistant and susceptible to the parasite
}

\author{
Ana Carolina Alves de Mattos ${ }^{1}$, Raquel Lopes Martins-Souza ${ }^{2}$, \\ John Robert Kusel ${ }^{3}$, Paulo Marcos Zech Coelho' ${ }^{1 /+}$ \\ 'Laboratório de Esquistossomose, Instituto de Pesquisa René Rachou-Fiocruz, Av. Augusto de Lima 1715, 30190-002 Belo Horizonte, MG, Brasil \\ ${ }^{2}$ Laboratório de Parasitologia, Universidade Federal de Alfenas, Alfenas, MG, Brasil \\ ${ }^{3}$ Division of Infection and Immunity, University of Glasgow, Scotland, UK
}

\begin{abstract}
The outcome of the interaction between Biomphalaria and Schistosoma mansoni depends on the response of the host internal defence system (IDS) and the escape mechanisms of the parasite. The aim of this study was to evaluate the responsiveness of the IDS (haemocytes and soluble haemolymph factors) of resistant and susceptible Biomphalaria tenagophila lineages and Biomphalaria glabrata lineages in the presence of in vitro-transformed primary sporocysts and secondary sporocysts obtained from infected $\mathrm{B}$. glabrata. To do this, we assayed the cellular adhesion index (CAI), analysed viability/mortality, used fluorescent markers to evaluate the tegumental damage and transplanted secondary sporocysts. B. tenagophila Taim was more effective against primary and secondary sporocystes than the susceptible lineage and B. glabrata. Compared with secondary sporocysts exposed to B. tenagophila, primary sporocysts showed a higher CAI, a greater percentage of dead sporocysts and were labelled by lectin from Glycine max and Alexa-Fluor 488 fluorescent probes at a higher rate than the secondary sporocysts. However, the two B. tenagophila lineages showed no cercarial shedding after inoculation with secondary sporocysts. Our hypothesis that secondary sporocysts can escape the $\mathrm{B}$. tenagophila IDS cannot be confirmed by the transplantation experiments. These data suggest that there are additional mechanisms involved in the lower susceptibilty of $\mathrm{B}$. tenagophila to S. mansoni infection.
\end{abstract}

Key words: Schistosoma mansoni - sporocysts - Biomphalaria tenagophila - internal defence system - escape mechanisms

Planorbidae of the genus Biomphalaria are the intermediate hosts of the parasite Schistosoma mansoni. A high degree of specificity is an important characteristic of the mollusc-digenea interaction. According to the literature, a restricted number of Biomphalaria species and lineages are susceptible to a specific strain of $S$. mansoni (Basch 1976). Biomphalaria glabrata, Biomphalaria tenagophila and Biomphalaria straminea are the three species responsible for the transmission of schistosomiasis in Brazil (Paraense 1975). Many authors (Corrêa et al. 1979, Santos et al. 1979, Bezerra et al. 1997, 2003, Martins-Souza et al. 2003, Rosa et al. 2004, 2005, 2006, Barbosa et al. 2006, Coelho et al. 2008, Pereira et al. 2008) have described the existence of a geographic lineage of B. tenagophila (provided from Ecological Station of Taim, state of Rio Grande do Sul, Brazil) resistant to S. mansoni. This lineage represents an important population in which to study the defence mechanisms of these invertebrate hosts to $S$. mansoni infection. The compatibility between $S$. mansoni and Biomphalaria is established by genetic factors of the parasite and of the

Financial support: CAPES, PRONEX-FAPEMIG, FIOCRUZ

+ Corresponding author: coelhopm@cpqrr.fiocruz.br

Received 18 November 2010

Accepted 16 February 2011 intermediate host (Adema \& Loker 1997). Biomphalaria has an internal defence system (IDS) composed of cells (haemocytes) and soluble haemolymph factors that are stimulated in the presence of parasites (van der Knaap \& Loker 1990, Gliński \& Jarosz 1997, Hahn et al. 2000, 2001). Parasite escape mechanisms that respond to the host IDS can assure the survival and adaptability of the parasite (Yoshino \& Bayne 1983, Adema \& Loker 1997). Previous studies have demonstrated that success of the infection depends on the parasite interfering with the mollusc IDS (Fryer \& Bayne 1990). The parasite can disturb the IDS by producing proteases (Yoshino et al. 1993) and by the action of enzymes that neutralise reactive oxygen species (Connors \& Yoshino 1990). In addition, it has been demonstrated that sporocysts release glycoproteins (excreted/secreted products) that bind to carbohydrate-binding receptors on the haemocyte cell surface to attenuate the initial cellular recognition of the parasite (Johnston \& Yoshino 2001). These molecules can inhibit IDS mechanisms (Adema \& Loker 1997) by suppressing the synthesis of many haemocyte molecules (Lodes et al. 1991) or by reducing haemocyte motility and phagocytic activity (Fryer \& Bayne 1990, Lodes \& Yoshino 1990). Other important parasite escape mechanisms include the use of molecular mimicry, likely through the production of sporocyst surface membrane molecules similar to those present on the host, and the ability of the parasite to absorb host antigens (Yoshino \& Bayne 1983, Damian 1987, Salzet et al. 2000, Lehr et al. 2008, 2010, Peterson et al. 2009, van Die \& Cummings 
2010). According to Salzet et al. (2000), the latter mechanism can prevent the recognition of the parasite by the host IDS. Furthermore, van Die and Cummings (2010) and Lehr et al. (2010) have suggested that glycans play a role in the parasite molecular mimicry process. Although the evolutionary advantages of this adaptive process for the parasite are well understood, it is not known how this process interferes with schistosomiasis (Salzet et al. 2000) or whether this mechanism could interfere with the snail's resistance mechanisms. To this end, the aim of this study was to evaluate the mechanisms of B. tenagophila Taim (resistant) and Cabo Frio (susceptible) IDS systems in the presence of primary sporocysts transformed in vitro and secondary sporocysts derived from infected snails. To accomplish this, we measured cellular adhesion, assayed sporocysts viability and mortality, evaluated the tegumental damage using fluorescent markers and transplanted secondary sporocysts.

\section{MATERIALS AND METHODS}

Snails and parasites - Snails B. tenagophila (Taim and Cabo Frio lineages) and B. glabrata (12-14 mm of diameter) and the $S$. mansoni LE strain were used in this work. The snails had been maintained for more than 30 years in the Mollusc Room of the René Rachou Research Center - Oswaldo Cruz Foundation.

Production of primary and secondary sporocysts Primary sporocysts were obtained from miracidia that were cultivated and transformed in vitro according to the technique described by Mattos et al. (2006) and Bahia et al. (2006). Briefly, livers of mice 50 days after infection with $S$. mansoni were macerated, sedimented and transferred to a glass flask containing $500 \mathrm{~mL}$ of water without chlorine. This flask was exposed to artificial light, and the miracidia were collected. The miracidia were transformed in Roswell Park Memorial Institute-1640 culture medium containing $5 \%$ foetal bovine serum (FBS) (Gibco Limited, Paisley, Scotland, UK) and $100 \mu \mathrm{g} / \mathrm{mL}$ penicillin/streptomycin antibiotics (Sigma) in biochemical oxygen demand (BOD) incubators at $26^{\circ} \mathrm{C}$ for $24 \mathrm{~h}$. The primary sporocysts were then washed with Chernin Balanced Saline Solution (CBSS) (pH 7.4; 100 mOsm).

The secondary sporocysts were obtained from $B$. glabrata infected with S. mansoni (Pereira et al. 1984). Briefly, the cephalopodal region from snails infected with 50 miracidia was dissected after 13 days of infection. This tissue, with the secondary sporocysts, was ground and fragments were transferred to a nylon mesh $(200 \mu \mathrm{m})$ and maintained in contact with CBSS (pH 7.4) for $2 \mathrm{~h}$ in a water bath at $28^{\circ} \mathrm{C}$. Next, CBSS from below the mesh was centrifuged at $1,000 \mathrm{rpm}$ for $2 \mathrm{~min}$ and the secondary sporocysts were counted under a microscope.

Haemolymph collection and counting of haemocytes - Whole haemolymph was collected from B. tenagophila (Taim and Cabo Frio lineages) and B. glabrata. Each snail shell was cleaned with $70 \%$ alcohol and maintained overnight in antibiotic solution (100 $\mu \mathrm{g} / \mathrm{mL}$ penicillin/ streptomycin and $4 \mathrm{mg}$ amphotericin B). Total haemolymph (TH fraction) was collected by cardiac puncture using a 21 G needle (Zelck \& Becker 1990, Bezerra et al.
1997) and centrifuged at $1,000 \mathrm{rpm}$ for $10 \mathrm{~min}$ at $4^{\circ} \mathrm{C}$. The supernatant was transferred to another tube $[(\mathrm{S})$ soluble fraction only] and the pelleted haemocytes were resuspended in CBSS supplemented with $2 \%$ essential aminoacids (Sigma), 5\% FBS and 2\% antibiotics penicillin/streptomycin; haemocytes were resuspended in a CBSS volume equal to the haemolymph that was initially collected $[(\mathrm{H})$ fraction of haemocytes only]. The haemocytes were then diluted 1/10 in CBSS solution containing $0.4 \%$ Trypan Blue and counted in a Neubauer's chamber (Martins-Souza et al. 2009). In the experiments, haemolymph from 15 snails was pooled and the post-separation fractions were called $\mathrm{TH}, \mathrm{H}$ or S.

Evaluation of the cellular adhesion index (CAI) and the viability/mortality of primary and secondary sporocysts after contact with B. tenagophila (Taim and Cabo Frio lineages) and B. glabrata IDS components - The experiments were performed in 24-well culture plates. Thirty microliters of S and TH fractions and $2 \times 10^{5} \mathrm{H}$ fraction from B. tenagophila (Taim and Cabo Frio lineages) and B. glabrata were separately exposed to 20 primary or secondary sporocysts. CBSS was then added for a final volume of $300 \mu \mathrm{L} /$ well. For measuring the CAI and for viability/mortality experiments, 10 wells were prepared for each lineage and each fraction; wells with only sporocysts were used as controls. The culture plates were maintained in BOD incubators at $26^{\circ} \mathrm{C}$. After $2 \mathrm{~h}$ incubation, 100 sporocysts from each lineage were analysed to determine their CAI using the protocol described by Castillo and Yoshino (2002). Sporocyst CAIs were scored as arbitrary values ranging from 1-4 according to the following parameters: CAI 1: no adherent haemocytes on the sporocyst surface; CAI 2: up to 10 adherent haemocytes; CAI 3: between 11-50 haemocytes; CAI 4: more than 50 adherent haemocytes. The formula to calculate CAI was:

$$
\mathrm{CAI}=\frac{\text { Total binding value }}{\text { Number of sporocysts scored }}
$$

The total binding value was obtained by summing the individual values (1-4) of all the sporocysts scored from each lineage and haemolymph fraction. The following statistical analyses were used: an unpaired, twotailed Student $t$ test/Mann-Whitney test (2-tailed) or the One-Way Analysis of Variance/Kruskal-Wallis and Dunn's Multiple Comparison test. Analyses were carried out using GraphPad Prism 4 software. Differences were considered significant if $\mathrm{p} \leq 0.05$.

Sporocyst viability was assessed $6 \mathrm{~h}$ post-incubation using an inverted microscope. The proportion of dead sporocysts was identified by $0.4 \%$ Trypan Blue staining. All the sporocysts present in each well were counted. The Chi-square test with Fisher's exact test (when necessary) was used to analyse the data. These tests were conducted using the Minitab 14 software.

Evaluation of primary and secondary sporocyst tegumental damage after contact with B. tenagophila (Taim and Cabo Frio lineages) IDS components - Thirty microliters of fractions $\mathrm{S}, \mathrm{TH}$ and $2 \times 10^{5} \mathrm{H}$ fraction from the $B$. tenagophila Taim and Cabo Frio lineages were separately 
incubated with 20 primary or secondary sporocysts in 24well culture plates. The volume of each well was topped up to $300 \mu \mathrm{L}$ with CBSS after the distribution of IDS and sporocysts. The culture plates were maintained in BOD incubators at $26^{\circ} \mathrm{C}$. Wells containing only sporocysts were used as a control. Six experimental wells were used for each lineage and each haemolymph fraction. After $3 \mathrm{~h}$ and $5 \mathrm{~h}$ of incubation, the sporocysts were labelled for 30 min with fluorescents probes Hoechst 33258 (a hydrophilic DNA-specific probe that binds with DNA only after damage to the cell membrane), lectin from Glycine $\max$ (soybean, specific for $\mathrm{N}$-acetylgalactosamine) and Alexa-Fluor 488 phalloidin (specific for actin filaments). The parasites were then washed three times with CBSS and analysed with a fluorescence microscope (K-Zeiss). The filters used were as follows: red for lectin from Glycine $\max$ TRITC (excitation/maximal emission 543/571 $\mathrm{nm}$ ), green for Alexa-Fluor 488 (excitation/maximal emission 499/520 nm) and blue for Hoechst 33258 (excitation/maximal emission 352/455 nm). Photographs were taken with a Canon EOS Digital Rebel XT camera. The colour histogram tool of the ImageJ 1.43 software was used to calculate mean fluorescence intensity/area for each image obtained in the experiments. Statistical analyses were performed using the Mann Whitney test (2-tailed) in the GraphPad Prism 4 software. Differences were considered significant if $\mathrm{p} \leq 0.05$.

Evaluating the development of secondary sporocysts from B. glabrata infected after sporocyst inoculations in B. tenagophila (Taim and Cabo Frio) and B. glabrata To determine whether the IDS from $B$. tenagophila Taim can recognise the secondary sporocysts obtained from $B$. glabrata, we inoculated $B$. tenagophila with parasites originally recovered from $B$. glabrata.

Thirty secondary sporocysts obtained from infected B. glabrata were inoculated into 65 B. tenagophila Taim and $B$. glabrata and into 35 B. tenagophila de Cabo Frio using a modified protocol described by Jourdane and Theron (1980). Briefly, snails were anaesthetised with sodium pentobarbital solution $(0.4 \mathrm{mg} / \mathrm{mL})$ for at least $6 \mathrm{~h}$ (Martins-Souza et al. 2001). A sample of secondary sporocysts was stained with Trypan Blue and the unstained parasites were counted. Next, the secondary sporocysts were inoculated (maximum $30 \mu \mathrm{L}$ ) into the cephalopodal area using a syringe and $30 \mathrm{G}$ needle. After inoculation for 14, 21, 27 and 35 days, the snails were exposed individually to artificial light for $1 \mathrm{~h}$ to verify the shedding of cercariae.

\section{RESULTS}

CAI of primary and secondary sporocysts - The CAI values are shown in Table I. The haemocytes from all Biomphalaria species were able to adhere to the surface of primary and secondary sporocysts. However, IDS of B. glabrata (mean CAI - TH: $1.89 \pm 0.31, \mathrm{H}: 1.87 \pm 0.35$ ) showed significantly lower CAI values compared to IDS of B. tenagophila Taim (mean CAI - TH: $2.13 \pm 0.25$, H: $2.02 \pm 0.22$ ) and Cabo Frio (mean CAI - TH: $2.32 \pm$ $0.3, \mathrm{H}: 1.98 \pm 0.31)(\mathrm{p}<0.03)$. Similarly, B. tenagophila Taim cell binding to secondary sporocysts (mean CAI -
TABLE I

Mean cellular adhesion index (CAI) values of Biomphalaria tenagophila (Taim and Cabo Frio) and Biomphalaria glabrata cells binding of primary and secondary sporocysts of Schistosoma mansoni

\begin{tabular}{lccc}
\hline & & $\begin{array}{c}\text { Primary } \\
\text { sporocysts } \\
\text { CAI } \pm \text { SD }\end{array}$ & $\begin{array}{c}\text { Secondary } \\
\text { sporocysts } \\
\text { CAI } \pm \text { SD }\end{array}$ \\
\hline B. tenagophila Taim & TH & $2.13 \pm 0.25^{b}$ & $2.03 \pm 0.31^{b}$ \\
B. tenagophila Cabo Frio & $\mathrm{H}$ & $2.02 \pm 0.22^{b}$ & $2.27 \pm 0.30^{a, b}$ \\
& $\mathrm{TH}$ & $2.32 \pm 0.3^{b, c}$ & $2.03 \pm 0.23^{b}$ \\
B. glabrata & $\mathrm{TH}$ & $1.98 \pm 0.31$ & $1.99 \pm 0.12^{b}$ \\
& $\mathrm{H}$ & $1.87 \pm 0.35^{c}$ & $1.73 \pm 0.41$ \\
& & & $1.41 \pm 0.2$ \\
\hline
\end{tabular}

$a$ : statistical difference between CAI of primary or secondary sporocysts exposed to $B$. tenagophila Taim and Cabo Frio internal defence system (IDS) [total hemolymph (TH) or fraction of hemocytes only $(\mathrm{H})]$ and CAI of primary or secondary sporocysts exposed to Cabo Frio IDS (TH or $\mathrm{H}) \mathrm{p}<0,03 ; b$ : statistical difference between CAI of primary or secondary sporocysts exposed to Taim IDS (TH or H) and CAI of primary or secondary sporocysts exposed to $B$. glabrata IDS (TH or $\mathrm{H}) \mathrm{p}<0,03$; $c$ : statistical difference betwen CAI of primary and secondary sporocysts exposed to IDS from the same species or lineage $(\mathrm{p}<0,02)$.

H: $2.27 \pm 0.30)$ was significantly higher $(\mathrm{p}<0.03)$ than to the secondary sporocysts exposed to Cabo Frio (mean CAI - H: $1.99 \pm 0.12$ ) and B. glabrata (mean CAI - H: 1.41 $\pm 0.2)$. Moreover, there were significantly $(\mathrm{p}<0.02)$ more cells adhering to the surface of primary sporocysts than of secondary sporocysts when they were exposed to $B$. tenagophila Cabo Frio (mean CAI - TH: $2.32 \pm 0.3$ ) and B. glabrata (mean CAI - H: $1.87 \pm 0.35$ ). There were no statistically significant differences between the different fractions of IDS (TH and $\mathrm{H}$ ) used in the experiments.

Viability/mortality of primary and secondary sporocysts - The results of the viability experiments are summarised in Table II. B. tenagophila Taim IDS resulted in significantly higher primary sporocysts mortality (TH $=47.5 \%, \mathrm{H}=58 \%, \mathrm{~S}=56 \%$ ) compared to IDS from $B$. tenagophila Cabo Frio $(\mathrm{TH}=23 \%, \mathrm{H}=32 \%, \mathrm{~S}=24.5 \%)$, B. glabrata $(\mathrm{TH}=5 \%, \mathrm{H}=18 \%, \mathrm{~S}=6 \%)$ and sporocysts control $(20 \%)(\mathrm{p}<0.03)$. However, the proportion of dead secondary sporocysts exposed to B. tenagophila Taim $(\mathrm{TH}=7 \%, \mathrm{H}=8.5 \%, \mathrm{~S}=6.5 \%)$ was significantly higher $(\mathrm{p}<0.03)$ only when compared to B. glabrata $(\mathrm{TH}=3 \%$, $\mathrm{H}=3 \%, \mathrm{~S}=2 \%$ ). On the other hand, we observed that the secondary sporocysts died at a significantly lower rate $(\mathrm{p}$ $<0.01)$ than the primary sporocysts when exposed to $B$. tenagophila Taim and Cabo Frio but not to B. glabrata.

Presence of tegumental damage in primary and secondary sporocysts after contact with mollusc IDS (HT, $H$ and $S$ fractions) - No differences were observed in the labelling of sporocysts analysed $3 \mathrm{~h}$ and $5 \mathrm{~h}$ after incubation with different fractions of haemolymph TH 
from each lineage. Tegumental damage was shown by Hoechst 33258 staining to be similar for all experimental conditions. However, primary sporocysts exposed to B. tenagophila Cabo Frio (mean fluorescence intensity/ area: $2.8 \pm 1.6)$ were significantly more labelled $(\mathrm{p}=0.03)$ than secondary sporocysts (mean fluorescence intensity/ area: $0.21 \pm 0.05$ ) (Fig. 1). Alexa-Fluor 488 was better in indicating the differences in the extent of tegument damage between the various experiments. The primary sporocysts exposed to Taim (mean fluorescence intensity/area: $2.5 \pm 0.8)$ presented significantly more $(p=0.04)$ tegumental damage than both the sporocysts exposed to Cabo Frio (mean fluorescence intensity/area: $1.1 \pm 0.84$ ) and control primary sporocysts (mean fluorescence intensity/area: $1.1 \pm 0.9$ ). Moreover, the primary sporocysts exposed to Taim were labelled at a significantly higher rate $(\mathrm{p}=0.04)$ than the secondary sporocysts (mean fluorescence intensity/area: $0.38 \pm 0.2$ ) (Fig. 2). A similar result was observed using lectin from Glycine max. Primary sporocysts exposed to Taim (mean fluorescence intensity/area: $2.76 \pm 0.8$ ) showed significantly higher $(\mathrm{p} \leq 0.03)$ labelling than the sporocysts exposed to Cabo Frio (mean fluorescence intensity/area: $0.47 \pm$

\section{TABLE II}

Proportion of dead primary and secondary sporocysts of Schistosoma mansoni after exposure of parasite to the internal defence systems (IDS) of Biomphalaria tenagophila Taim (resistant), Cabo Frio (susceptible) and Biomphalaria glabrata

\begin{tabular}{|c|c|c|c|}
\hline Groups of IDS & & $\begin{array}{c}\text { Dead primary } \\
\text { sporocysts } \\
(\%)\end{array}$ & $\begin{array}{c}\text { Dead secondary } \\
\text { sporocysts } \\
(\%)\end{array}$ \\
\hline \multirow[t]{3}{*}{ B. tenagophila Taim } & $\mathrm{TH}$ & $47.5^{a, b, c, d}$ & $7^{b}$ \\
\hline & $\mathrm{H}$ & $58^{a, b, c, d}$ & $8.5^{b}$ \\
\hline & S & $56^{a, b, c, d}$ & $6.5^{b}$ \\
\hline \multirow[t]{3}{*}{ B. tenagophila Cabo Frio } & $\mathrm{TH}$ & $23^{b, d}$ & $9^{c}$ \\
\hline & $\mathrm{H}$ & $32^{d}$ & 5 \\
\hline & $\mathrm{S}$ & $24.5^{b, d}$ & 5.5 \\
\hline \multirow[t]{3}{*}{ B. glabrata } & $\mathrm{TH}$ & $5^{c}$ & 3 \\
\hline & $\mathrm{H}$ & $18^{d}$ & 3 \\
\hline & $\mathrm{S}$ & $6^{c}$ & 2 \\
\hline Control & - & 20 & 6 \\
\hline
\end{tabular}

a: statistical difference between proportion of dead primary or secondary sporocysts exposed to B. tenagophila Taim and Cabo Frio IDS and proportion of dead primary or secondary sporocysts exposed to Cabo Frio IDS ( $\mathrm{p}<0.03) ; b$ : statistical difference between proportion of dead primary or secondary sporocysts exposed to Taim IDS and proportion of dead primary or secondary sporocysts exposed to B. glabrata IDS (p $<0.03$ ); $c$ : statistical difference between proportion of dead primary or secondary sporocysts exposed to Taim IDS and proportion of dead primary or secondary control sporocysts $(\mathrm{p}<0.03) ; d$ : statistical difference between proportion of primary and secondary sporocysts exposed to IDS from the same species or lineage ( $\mathrm{p}<0.01)$; H: fraction of hemocytes only; $\mathrm{S}$ : only soluble fraction; TH: total hemolymph.
0.43 ) and sporocysts control (mean fluorescence intensity/area: $0.7 \pm 0.6$ ) and higher labelling than secondary sporocysts exposed Taim (mean fluorescence intensity/ area: $0.12 \pm 0.06)$ (Fig. 3). The labelling intensities for all experimental conditions are shown in the Figs 4-6.

Development of secondary sporocysts isolated from B. glabrata and inoculated into B. tenagophila (Taim and Cabo Frio) and B. glabrata - Sixty-five B. tenagophila Taim were inoculated with secondary sporocysts provided from infected B. glabrata. Thirty days after inoculation, only seven snails were alive (11\%) and none were shedding cercariae. Of the 35 B. tenagophila Cabo Frio similarly inoculated with $B$. glabrata-derived secondary sporocysts, 11 snails were alive at the end of the

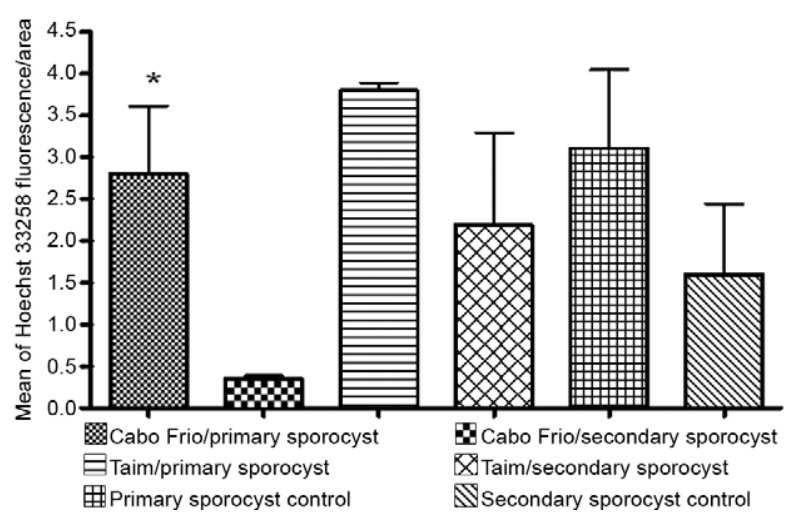

Fig. 1: mean Hoechst 33258 fluorescence/area in primary and secondary sporocysts exposed to internal defence systems of Biomphalaria tenagophila from Taim or Cabo Frio lineage and sporocysts control. Asterisk means difference between primary and secondary sporocysts exposed to Cabo Frio $(\mathrm{p}=0.03)$.

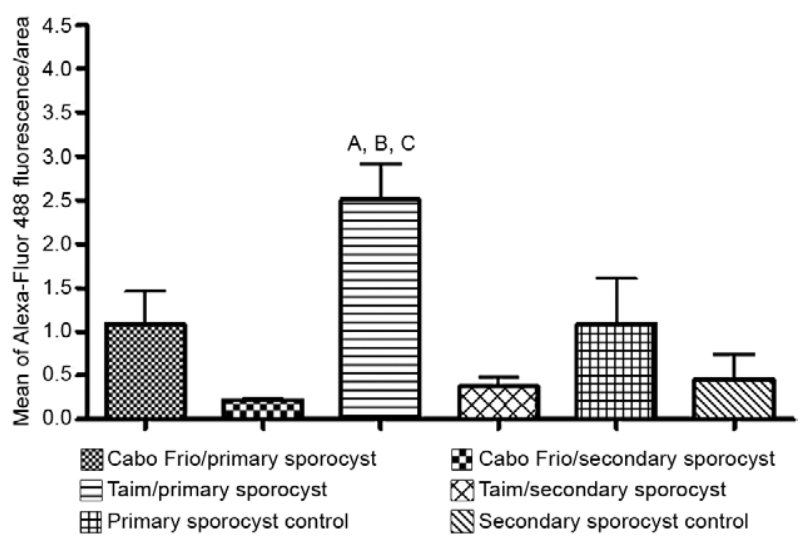

Fig. 2: mean Alexa-Fluor 488 fluorescence/area in primary and secondary sporocysts exposed to internal defence systems of Biomphalaria tenagophila from Taim or Cabo Frio lineage and sporocysts control. A: difference between primary sporocysts exposed to Cabo Frio and primary sporocysts exposed to Taim $(p=0.04)$; B: difference between primary and secondary sporocysts exposed to Taim ( $p$ $=0.03)$; : difference between primary sporocysts exposed to Taim and primary sporocysts control $(\mathrm{p}=0.04)$. 
experiments (31\%). The survival of B. tenagophila Cabo Frio was high, but all the snails were negative for cercariae. Sixty-five B. glabrata were inoculated with secondary sporocysts provided from snails of the same species. At the end of the experiments, 21 snails were alive (32\%) and $11(52 \%)$ were shedding cercariae (Table III).

\section{DISCUSSION}

Biomphalaria tenagophila from Taim is resistant to S. mansoni. However, the mechanisms used to eliminate the parasite are not completely understood (Coelho et al. 2008). In this study, we sought to demonstrate the efficacy of the IDS from $B$. tenagophila (resistant and susceptible strains) and B. glabrata. We used primary sporocysts produced in vitro and secondary sporocysts derived from B. glabrata. We also used a transplantation technique to assess the survival of secondary sporocysts derived from $B$. glabrata. Our hypothesis was that secondary sporocysts (from $B$. glabrata) would be less recognised or not recognised at all by the B. tenagophila Taim IDS because of the presence of host molecules on the sporocysts' surface. This concept of molecular mimicry was introduced by Yoshino and Bayne (1983) when they found haemolymph-like antigens on the surface tegument of sporocysts. Similar mimicry has been suggested in schistosomula by Guillou et al. (2007) and Horta and Ramalho-Pinto (1991) by demonstrating that decay-accelerating factor from human erythrocytes could be transferred to $S$. mansoni and protect it against complement-mediated haemolysis. We observed that the secondary sporocysts were recognised at a lower rate than the primary sporocysts in the in vitro experiments. This can likely be explained by the sporocysts acquiring or producing protein during their previous contact with the snail host, rendering them resistant to haemocytic

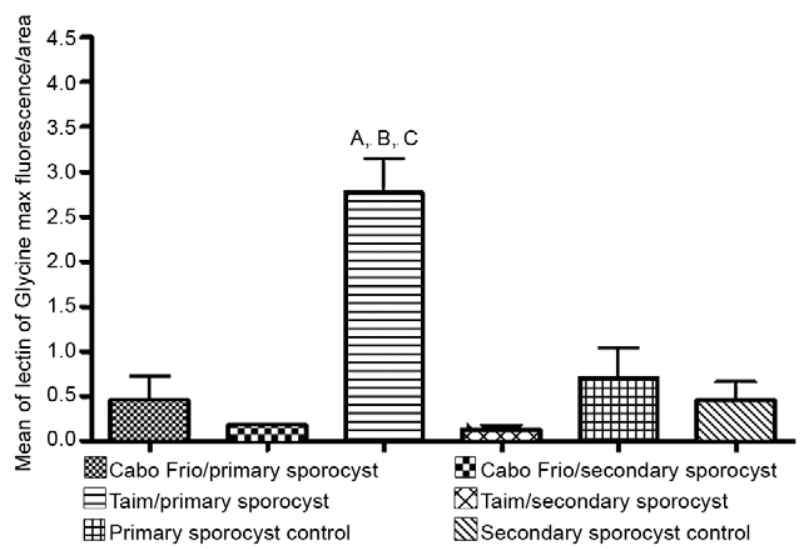

Fig. 3: mean lectin of Glycine max fluorescence/area in primary and secondary sporocysts exposed to internal defence systems of Biomphalaria tenagophila from Taim or Cabo Frio lineage and sporocysts control. A: difference between primary sporocysts exposed to Cabo Frio and primary sporocysts exposed to Taim $(\mathrm{p}=0.007)$; B: difference between primary and secondary sporocysts exposed to Taim ( $p$ $=0.03$ ); $\mathrm{C}$ : difference between primary sporocysts exposed to Taim and primary sporocysts controls $(\mathrm{p}=0.03)$. attack. However, no infection occurred when $B$. tenagophila were challenged with secondary sporocysts. We therefore speculated that perhaps $B$. tenagophila might recognise the molecules from $B$. glabrata on the sporocyst surface as "non-self" because the snails are different species. Another possible hypothesis is that $B$. tenagophila were able to destroy the secondary sporocysts in the same way as primary sporocysts in vitro. Thus, mimicry can be a valid strategy for IDS escape, but it is likely assisted by another mechanism. We hypothesised that additional mechanisms might be revealed during the transplantation experiment.

We used different haemolymph fractions (TH, $\mathrm{H}$ and S) to investigate whether the presence of soluble factors could increase the activity of haemocytes. We found no statistical difference between the fractions, indicating that the soluble factors did not increase haemocyte activity. Perhaps the amount of soluble factors used here $(10 \%$ of total volume) was not sufficient to achieve a demonstrable effect on the haemocytes. Pereira et al. (2008) observed that when the fraction of soluble factors was $20 \%$ of the total volume, this produced an enhanced effect on haemocytes. Our analyses of the CAI showed
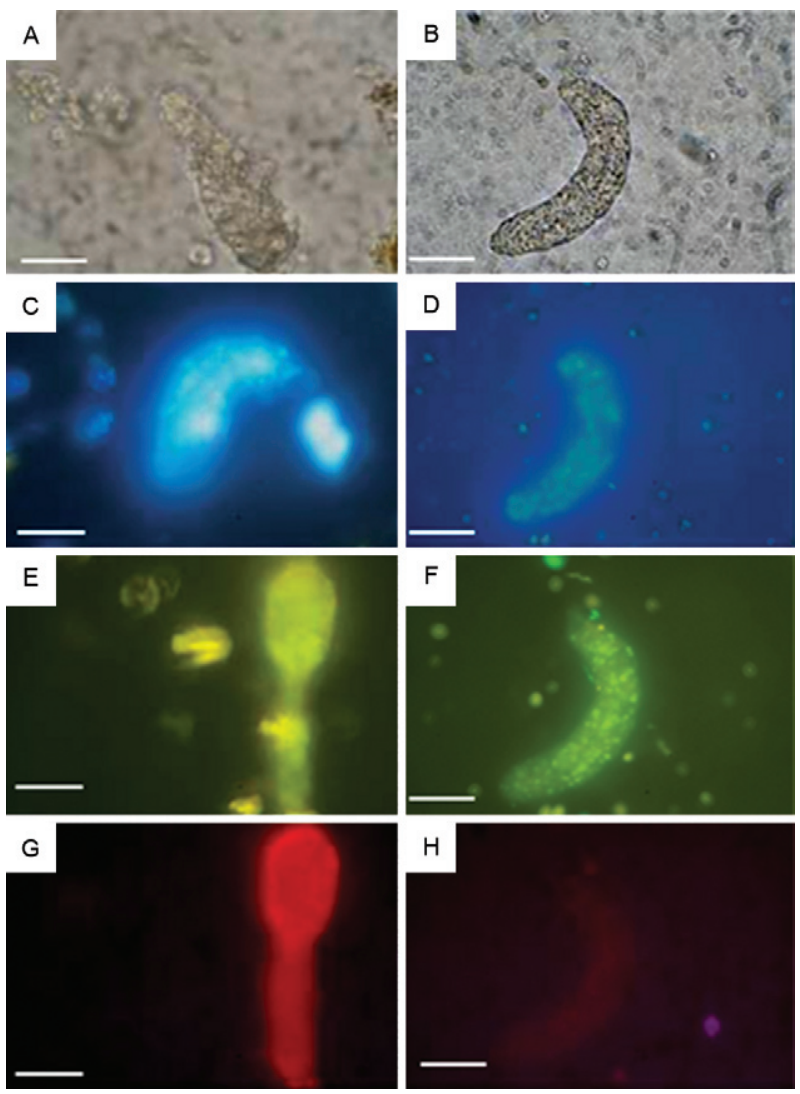

Fig. 4: action of internal defence systems of Biomphalaria tenagophila from Taim on the membrane of primary $(\mathrm{A}, \mathrm{C}, \mathrm{E}, \mathrm{G})$ and secondary (B, D, F, H) sporocysts. A, B: optical microscopy; C, D: labeled with Hoechst 33258 (fluorescence microscopy); E, F: labeled with AlexaFluor 488 (fluorescence microscopy); G, H: labeled with lectin of Glycine $\max$ (fluorescence microscopy). Bars $=25 \mu \mathrm{m}$. 
that in contact with the IDS of $B$. tenagophila Cabo Frio and $B$. glabrata, primary sporocysts presented higher CAI values than the secondary sporocysts, suggesting a better recognition of this intramollusc primary stage. On the other hand, haemocytes from Taim (which is resistant to $S$. mansoni infection) were able to adhere equally well to the primary and secondary sporocysts. In addition, the primary and secondary sporocysts exposed to B. tenagophila Taim presented the highest CAI value of all snails tested. In the viability/mortality experiments, the greatest percentage of dead primary and secondary sporocysts were observed upon exposure to $B$. tenagophila Taim and B. tenagophila Cabo Frio. Furthermore, both $B$. tenagophila Taim and Cabo Frio were able to kill more primary than secondary sporocysts. These results suggest that the Biomphalaria are more effective in recognising primary sporocysts than secondary sporocysts. We observed a higher mortality in the control sporocysts than the sporocysts exposed to B. glabrata. This could be because $B$. glabrata, which is most susceptible to $S$. mansoni infection, may produce molecules that can increase the sporocyst survival. The results using fluorescent probes corroborate to those previously described. B. tenagophila Taim causes more damage to the tegumental surface of primary sporocysts. The primary sporocysts exposed to B. tenagophila Taim were labelled with Alexa-Fluor 488 and lectin from Glycine max at a greater rate than those inoculated into $B$. tenagophila Cabo Frio and the control sporocysts, and the primary sporocysts exposed to B. tenagophila Taim were labelled at a greater rate with Alexa-Fluor 488 and lectin from Glycine max than those sporocysts exposed to $B$. tenagophila Cabo Frio and the control sporocysts, and the primary sporocysts exposed to B. tenagophila Taim showed higher Alexa-Fluor 488 and lectin from Glycine max labelling intensities than secondary sporocysts. The probe Hoechst 33258 is used to assay membrane integrity and is thus a very sensitive probe for labelling tegument damage; even small amounts of tegument damage can be detected by this probe (Mattos et al. 2006, Oliveira et al. 2006). A similar sensitivity is not observed for the lectin from Glycine max (Mattos et al. 2006 in sporocyst) or Alexa-Fluor 488 (Oliveira et al. 2006 in adult worms). Consistent with these earlier results, only the sporocysts with intense damage were labelled with Alexa-Fluor 488 and lectin from Glycine max. These results demonstrate that damage by Taim IDS causes more $\mathrm{N}$-acetylgalactosamine to be exposed on the parasite
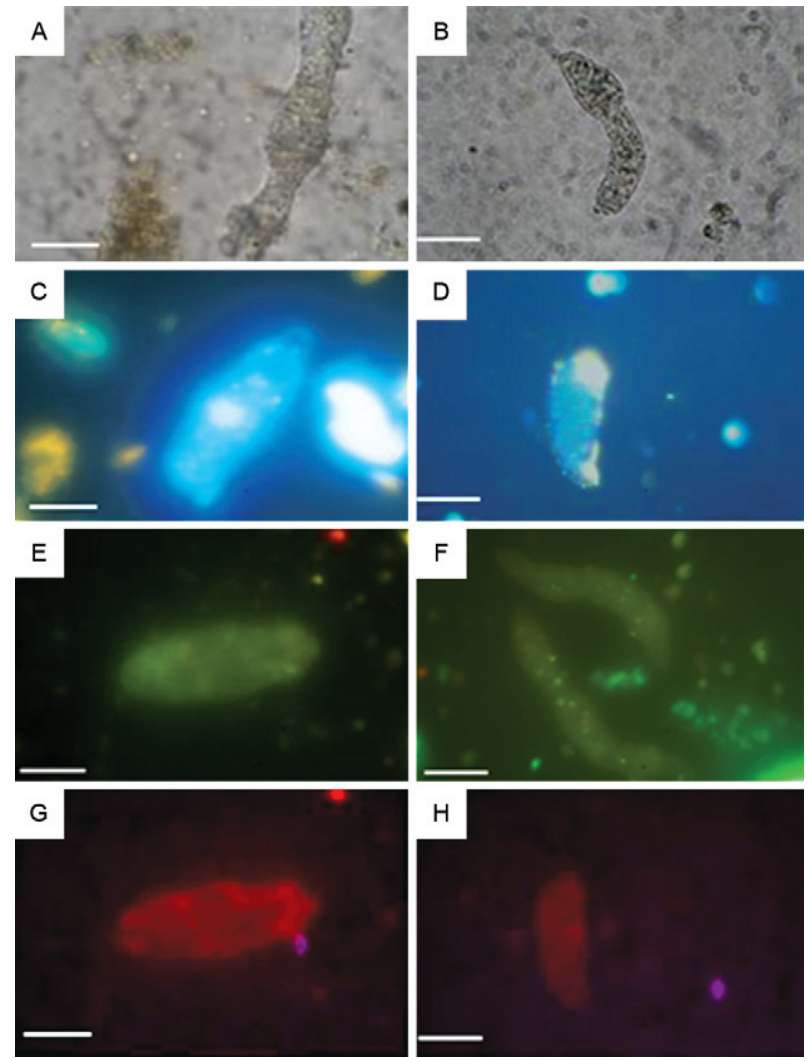

Fig. 5: action of internal defence systems of Biomphalaria tenagophila from Cabo Frio on the membrane of primary (A, C, E, G) and secondary (B, D, F, H) sporocysts. A, B: optical microscopy; C, D: labeled with Hoechst 33258 (fluorescence microscopy); E, F: labeled with Alexa-Fluor 488 (fluorescence microscopy); G, H: labeled with lectin of Glycine max (fluorescence microscopy). Bars $=25 \mu \mathrm{m}$.
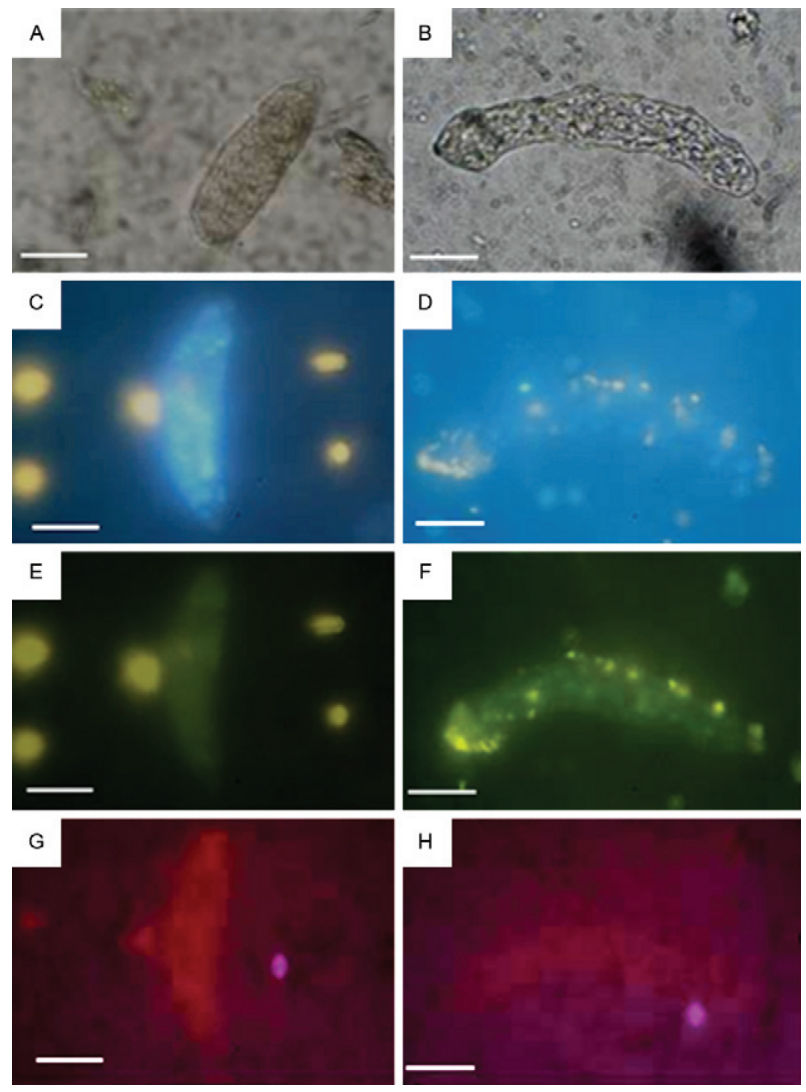

Fig. 6: primary (A, C, E, G) and secondary (B, D, F, H) sporocysts control. A, B: optical microscopy; C, D: labeled with Hoechst 33258 (fluorescence microscopy); E, F: labeled with Alexa-Fluor 488 (fluorescence microscopy); G, H: labeled with lectin of Glycine max (fluorescence microscopy). Bars $=25 \mu \mathrm{m}$. 
TABLE III

Numbers and percentage of alive and infected snails 30 days after inoculation with secondary sporocysts of Schistosoma mansoni

\begin{tabular}{lccc}
\hline Species/lineages & $\begin{array}{c}\text { Inoculated } \\
\text { snails }\end{array}$ & $\begin{array}{c}\text { Alive snails } \\
(\%)\end{array}$ & $\begin{array}{c}\text { Infected snails } \\
(\%)\end{array}$ \\
\hline Biomphalaria tenagophila Taim & 65 & $7(11)$ & 0 \\
B. tenagophila Cabo Frio & 35 & $11(31)$ & 0 \\
Biomphalaria glabrata & 65 & $21(32)$ & $11(52)$ \\
\hline
\end{tabular}

surface. Likewise, the Alexa-probe 488 labels the actin under the sporocyst surface. We attempted to infect $B$. tenagophila Taim and Cabo Frio with secondary sporocysts derived from B. glabrata; however, at the end of the experiments, only $B$. glabrata molluscs were infected. These data suggest that $B$. tenagophila Taim and Cabo Frio may recognise and destroy parasites derived from another Biomphalaria species. In addition, the mortality of $B$. tenagophila Taim was higher than that of the other snails. It has been well established that $B$. tenagophila Taim is completely resistant to $S$. mansoni (Corrêa et al. 1979, Santos et al. 1979, Bezerra et al. 1997, 2003, Martins-Souza et al. 2003, Rosa et al. 2004, 2005, 2006, Barbosa et al. 2006, Coelho et al. 2008, Pereira et al. 2008). Table II shows that $B$. tenagophila Taim kills sporocysts more effectively than the Cabo Frio strain or B. glabrata. Because the control values in Table II are high, it is not clear whether sporocysts are killed by B. glabrata or by the Cabo Frio strain.

The tegument of $S$. mansoni sporocysts is an important interface for molecular communication between the parasite and Biomphalaria (Johnston \& Yoshino 1996). According to Loker (1994), the sporocyst's tegument is the main target for the snail's IDS. The haemocytes from resistant mollusc can recognise, encapsulate and destroy the sporocysts soon after $S$. mansoni invasion. However, the ability of parasites to avoid or disrupt the host's immune response is fundamental to the establishment of parasite-host compatibility (Yoshino \& Bayne 1983). Similar molecules have been found in S. mansoni and in Biomphalaria, suggesting an evolutionary convergence of molecular expression between schistosomes and their snail hosts (Basch 1976, Yoshino \& Bayne 1983, Peterson et al. 2009, van Die \& Cummings 2010, Lehr et al. 2010). One may hypothesise that the similarity of these molecules is important for the escape process of the parasite; this hypothesis is known as molecular mimicry (Lehr et al. 2008, 2010). In these experiments, we used primary sporocysts transformed in vitro from miracidia and secondary sporocysts isolated from infected B. glabrata; these different intramollusc stages may present distinct surface molecules. The carbohydrates of glycoproteins and glycolipids represent the major chemical components of the schistosome intramollusc stage (Zelck \& Becker 1990, Uchikawa \& Loker 1991). These carbohydrates can be recognised by lectins present in the snail's IDS and it has been demonstrated that lectins play an important role in the parasite/mollusc interaction (Uchikawa \& Loker 1991, Johnston \& Yoshino 1996, Martins-Souza et al. 2006). Lectins (carbohydrate-binding proteins) are also important receptors for the non-self recognition capabilities of snails and others invertebrates (Renwrantz 1986).

These results indicate that the techniques used here can be performed to test whether carbohydrates on the parasite surface represent a form of molecular mimicry. Future work will use the Taim IDS to detect changes in carbohydrates on the sporocyst surface (induced by glycosidases, for example) and further comparisons between sporocysts isolated from B. glabrata and B. tenagophila may reveal those molecules recognised by the Taim IDS in transplantation experiments.

\section{ACKNOWLEDGEMENTS}

To the technicians of the Mollusc Room of the René Rachou Research Center-Fiocruz, for maintenance of the parasite life cycle.

\section{REFERENCES}

Adema CM, Loker ES 1997. Specificity and immunobiology of larval digenean-snail associations. In B Fried, TK Graczyk, Advances in trematode biology, CRC Press, Boca Raton, p. 229-264.

Bahia D, Avelar LG, Vigorosi F, Cioli D, Oliveira GC, Mortara RA 2006. The distribution of motor proteins in the muscles and flame cells of the Schistosoma mansoni miracidium and primary sporocyst. Parasitology 133: 321-329.

Barbosa L, Caldeira RL, Carvalho OS, Vidigal TH, Jannotti-Passos LK, Coelho PM 2006. Resistance to Schistosoma mansoni by transplantation of APO Biomphalaria tenagophila. Parasite Immunol 28: 209-212.

Basch PF 1976. Intermediate host specificity in Schistosoma mansoni. Exp Parasitol 39: 150-169.

Bezerra FSM, Nogueira-Machado JA, Chaves MM, Martins RL, Coelho PM 1997. Quantification of the population and phagocytary activity of hemocytes of resistant and susceptible strains of Biomphalaria glabrata and Biomphalaria tenagophila infected with Schistosoma mansoni. Rev Inst Med Trop Sao Paulo 39: 197-201.

Bezerra FSM, Nogueira-Machado JA, Martins-Souza RL, Chaves MM, Correa RF, Coelho PMZ 2003. Effect of gamma radiation on the activity of hemocytes and on the course of Schistosoma mansoni infection in resistant Biomphalaria tenagophila snails. Mem Inst Oswaldo Cruz 98: 73-75.

Castillo MG, Yoshino TP 2002. Carbohydrate inhibition of Biomphalaria glabrata embryonic (Bge) cell adhesion to primary sporocysts of Schistosoma mansoni. Parasitology 125: 513-525. 
Coelho PMZ, Rosa FM, Maciel E, Negrão-Correa DA, Carvalho OS, Caldeira RL, Jannotti-Passos LK, Moreira LA, Oliveira GC, Teles HM 2008. Transmission control of schistosomiasis mansoni by introduction of a resistant strain of Biomphalaria tenagophila in areas where transmission is maintained by this species. Acta Trop 108: 245-248.

Connors VA, Yoshino TP 1990. In vitro effect of larval Schistosoma mansoni excretory-secretory products on phagocytosis-stimulated superoxide production in hemocytes from Biomphalaria glabrata. J Parasitol 76: 895-902.

Corrêa MCR, Coelho PMZ, Freitas JR 1979. Suscetibilidade de linhagens de Biomphalaria tenagophila e Biomphalaria glabrata a duas cepas de Schistosoma mansoni (LE - Belo Horizonte - MG e SJ São José dos Campos, SP). Rev Inst Med Trop Sao Paulo 21: 72-76.

Damian RT 1987. Molecular mimicry revisited. Parasitol Today 3: 263-266.

Fryer SE, Bayne CJ 1990. Schistosoma mansoni modulation of phagocytosis in Biomphalaria glabrata. J Parasitol 76: 45-52.

Gliński Z, Jarosz J 1997. Molluscan immune defences. Arch Immunol Ther Exp (Warsz) 45: 149-155.

Guillou F, Roger E, Moné Y, Rognon A, Grunau C, Théron A, Mitta G, Coustau C, Gourbal BE 2007. Excretory-secretory proteome of larval Schistosoma mansoni and Echinostoma caproni, two parasites of Biomphalaria glabrata. Mol Biochem Parasitol 155: 45-56.

Hahn UK, Bender RC, Bayne CJ 2000. Production of reactive oxygen species by hemocytes of Biomphalaria glabrata: carbohydratespecific stimulation. Dev Comp Immunol 24: 531-541.

Hahn UK, Bender RC, Bayne CJ 2001. Involvement of nitric oxide in killing of Schistosoma mansoni sporocysts by hemocytes from resistant Biomphalaria glabrata. J Parasitol 87: 778-785.

Horta MF, Ramalho-Pinto FJ 1991. Role of human decay-accelerating factor in the evasion of Schistosoma mansoni from the complement-mediated killing in vitro. J Exp Med 174: 1399-1406.

Johnston LA, Yoshino TP 1996. Analysis of lectin- and snail plasma-binding glycopeptides associated with the tegumental surface of the primary sporocysts of Schistosoma mansoni. Parasitology 112: 469-479.

Johnston LA, Yoshino TP 2001. Larval Schistosoma mansoni excretory-secretory glycoproteins (ESPs) bind to hemocytes of Biomphalaria glabrata (Gastropoda) via surface carbohydrate binding receptors. J Parasitol 87: 786-793.

Jourdane J, Theron A 1980. Schistosoma mansoni: cloning by microsurgical transplantation of sporocysts. Exp Parasitol 50: 349-357.

Lehr T, Beuerlein K, Doenhoff MJ, Grevelding CG, Geyer R 2008. Localization of carbohydrate determinants common to Biomphalaria glabrata as well as to sporocysts and miracidia of Schistosoma mansoni. Parasitology 135: 931-942.

Lehr T, Frank S, Natsuka S, Geyer H, Beuerlein K, Doenhoff MJ, Hase S, Geyer R 2010. N-glycosylation patterns of hemolymph glycoproteins from Biomphalaria glabrata strains expressing different susceptibility to Schistosoma mansoni infection. Exp Parasitol 126: 592-602.

Lodes MJ, Connors VA, Yoshino TP 1991. Isolation and functional characterization of snail hemocyte-modulating polypeptide from primary sporocysts of Schistosoma mansoni. Mol Biochem Parasitol 49: 1-10.

Lodes MJ, Yoshino TP 1990. The effect of schistosome excretorysecretory products on Biomphalaria glabrata hemocyte motility. J Invertebr Pathol 56: 75-85.
Loker ES 1994. On being a parasite in an invertebrate host: a short survival course. J Parasitol 80: 728-747.

Martins-Souza RL, Negrão-Corrêa D, Bezerra FSM, Coelho PMZ 2001. Anesthesia of Biomphalaria spp (Mollusca, Gastropoda): sodium pentobarbital is the drug of choice. Mem Inst Oswaldo Cruz 96: 391-392.

Martins-Souza RL, Pereira CA, Coelho PM, Martins-Filho OA, Negrão-Corrêa D 2009. Flow cytometry analysis of the circulating haemocytes from Biomphalaria glabrata and Biomphalaria tenagophila following Schistosoma mansoni infection. Parasitology 136: $67-76$.

Martins-Souza RL, Pereira CA, Coelho PMZ, Negrão-Corrêa D 2003. Silica treatment increases the susceptibility of the Cabo Frio strain of Biomphalaria tenagophila to Schistosoma mansoni infection but does not alter the natural resistance of the Taim strain. Parasitol Res 91: 500-507.

Martins-Souza RL, Pereira CAJ, Martins Filho OA, Coelho PMZ, Corrêa A Jr, Negrão-Corrêa D 2006. Differential lectin labelling of circulating hemocytes from Biomphalaria glabrata and Biomphalaria tenagophila resistant or susceptible to Schistosoma mansoni infection. Mem Inst Oswaldo Cruz 101 (Suppl. I): $185-192$.

Mattos ACA, Kusel JR, Pimenta PFP, Coelho PMZ 2006. Activity of praziquantel on in vitro transformed Schistosoma mansoni sporocysts. Mem Inst Oswaldo Cruz 101 (Suppl. I): 283-287.

Oliveira FA, Kusel JR, Ribeiro F, Coelho PM 2006. Responses of the surface membrane and excretory system of Schistosoma mansoni to damage and to treatment with praziquantel and other biomolecules. Parasitology 132: 321-330.

Paraense WL 1975. Estado atual da sistemática dos Planorbídeos brasileiros. Arq Mus Nac 55: 105-111.

Pereira CA, Martins-Souza RL, Corrêa A Jr, Coelho PM, NegrãoCorrêa D 2008. Participation of cell-free haemolymph of Biomphalaria tenagophila in the defence mechanism against Schistosoma mansoni sporocysts. Parasite Immunol 30: 610-619.

Pereira LH, Valadares TE, da Cunha ML, Correa MC 1984. Recovery of young daughter sporocysts from snails infected with Schistosoma mansoni. Trans R Soc Trop Med Hyg 78: 563.

Peterson NA, Hokke CH, Deelder AM, Yoshino TP 2009. Glycotope analysis in miracidia and primary sporocysts of Schistosoma mansoni: differential expression during the miracidium-to-sporocyst transformation. Int J Parasitol 39: 1331-1344.

Renwrantz LR 1986. Immune mechanisms in invertebrate vectors. Lectins in molluscs and arthropods: their occurrence, origin and roles in immunity, vol. 81, Ann Lackie, Oxford, 299 pp.

Rosa FM, Caldeira RL, Carvalho O dos S, Godard ALB, Coelho PMZ 2004. Dominant character of the molecular marker of a Biomphalaria tenagophila strain (Mollusca: Planorbidae) resistant to Schistosoma mansoni. Mem Inst Oswaldo Cruz 99: 85-87.

Rosa FM, Godard ALB, Azevedo V, Coelho PMZ 2005. Biomphalaria tenagophila: dominant character of the resistance to Schistosoma mansoni in descendants of crossbreedings between resistant (Taim, RS) and susceptible (Joinville, SC) strains. Mem Inst Oswaldo Cruz 100: 19-23.

Rosa FM, Godard ALB, Negrão-Correa D, Rodrigues HA, Carvalho OS, Caldeira RL, Teles HMS, Maciel E, Jannotti-Passos LK, Coelho PMZ 2006. Biomphalaria tenagophila: dynamics of populations of resistant and susceptible strains to Schistosoma mansoni with or without pressure of the parasite. Mem Inst Oswaldo Cruz 101 (Suppl. I): 247-251. 
Salzet M, Capron A, Stefano GB 2000. Molecular crosstalk in hostparasite relationships: schistosome- and leech-host interactions. Parasitol Today 16: 536-540.

Santos MBL, Freitas JR, Correa MCR, Coelho PMZ 1979. Susceptibilidade ao Schistosoma mansoni de híbridos de Biomphalaria tenagophila to Taim, RS, Cabo Frio, RJ, e Belo Horizonte, MG. Rev Inst Med Trop Sao Paulo 21: 281-286.

Uchikawa R, Loker ES 1991. Lectin-binding properties of the surfaces of in vitro-transformed Schistosoma mansoni and Echinostoma paraensei sporocysts. J Parasitol 77: 742-748.

van der Knaap WP, Loker ES 1990. Immune mechanisms in trematode-snail interactions. Parasitol Today 6: 175-182. van Die I, Cummings RD 2010. Glycan gimmickry by parasitic helminths: a strategy for modulating the host immune response? Glycobiology 20: 2-12.

Yoshino TP, Bayne CJ 1983. Mimicry of snail host antigens by miracidia and primary sporocysts of Schistosoma mansoni. Parasite Immunol 5: 317-328.

Yoshino TP, Lodes MJ, Rege AA, Chappell CL 1993. Proteinase activity in miracidia, transformation excretory-secretory products and primary sporocysts of Schistosoma mansoni. J Parasitol 79: 23-31.

Zelck U, Becker W 1990. Lectin binding to cells of Schistosoma mansoni sporocysts and surrounding Biomphalaria glabrata tissue. J Invertebr Pathol 55: 93-99. 